\title{
THE PROGNOSIS IN JUVENILE OBESITY
}

\author{
BY \\ A. G. MULLINS \\ From St. James's Hospital, Balham, London
}

(RECEIVED FOR PUBLICATION NOVEMBER 7,1957 )

Juvenile obesity is common. Probably few paediatricians or general practitioners regard it as a serious medical problem. It has not been shown to be associated with high mortality or morbidity rates and, except in the most extreme cases, it is widely regarded as a benign if unsightly condition, usually associated with excessive eating and with tendencies both to improve and to persist. Recently the psychiatric aspects of the condition have aroused interest, and extensive studies have been published (Bruch, 1939, 1940, 1941, 1957; Juel-Nielsen, 1953; Iversen, 1953; Østergaard, 1954).

The exact incidence of juvenile obesity in this country is not known. Johnson, Burke and Mayer (1956) studying a cross-section of elementary and secondary schoolchildren in Boston, found that it occurred in $9 \%$ of the boys and in $12.5 \%$ of the girls in 6,000 children. It is doubtful whether the incidence is as high in this country. There is evidence that in some parts of the world its incidence is rising. In Germany, Haase and Hosenfeld (1956) found that, whereas its incidence fell enormously during the war, there are now five times as many cases seen in their clinic as in 1939.

A search of the literature failed to reveal any investigation of the ultimate dangers of juvenile obesity.

Obesity in adults is now one of the greatest medical problems in the western world and its dangers have been intensively studied. Obesity is known to shorten the life of animals (McCay, Maynard, Sperling and Osgood, 1941 ; Hansson, Brännäng and Claesson, 1953; Kennedy, 1951, 1955). For a long time insurance companies have known that among adults accepted for life insurance overweight of all degrees and at all ages is associated with a high mortality and morbidity. The subject has recently been reviewed by Armstrong, Dublin, Wheatley and Marks (1951) and by Marks (1956). Dublin (1953) points out that the relative increase of mortality in the overweight is increasing, since diseases in which mortality is higher in the underweight, chiefly pulmonary tuberculosis and pneumonia, are declining.

Probably the mortality of the obese as a class is even higher than insurance statistics suggest, since the subjects from whom the statistics were obtained were chosen as good insurance risks (Evans, 1952). Sinclair (1954) has said that if you are in middle life or more, your chances of dying early are greater if you are $10 \mathrm{lb}$. overweight than are your chances of getting carcinoma of the bronchus if you are a heavy smoker. Jolliffe (1953) calculated that if a cure were found for carcinoma, the average life expectancy would be increased by two years, whereas if obesity were cured, it would be increased by four years.

The part played in this state of affairs by persistent juvenile obesity has not been worked out. Few long-term results of treatment in this condition have been published, and authorities differ in their opinions. Gurney (1936) studied 63 fat women and found that eight of them had been obese all their lives and a further four since puberty; thus persistent juvenile and pubertal obesity existed in approximately $19 \%$ of his cases. Ellis and Tallerman (1934) state: 'It is well known that the majority of obese children tend to gravitate toward the normal after puberty has been reached.' Le Marquand (1951) found that a large proportion of fat girls traced to adult life either remained fat or became fat again after childbirn. Bornhardt (1936) re-investigated 65 obese children while they were in their teens and found that girls tended to remain obese more frequently than boys. Mossberg (1948) followed up 328 patients who had been admitted to hospital for obesity in childhood and found that the prognosis was worse in girls than in boys. Hering (1938) re-investigated 30 patients, and found that 10 were normal, 10 were 'giants', 
i.e. both tall and overweight but without giving an impression of obesity, and 10 were still obese. Hässler (1935) obtained similar results. Haase and Hosenfeld (1956) followed up 21 boys and 24 girls who had been treated before the war, and found that in most of them the condition had persisted. Some of them had lost weight at puberty or during the war, but of these, most had again become obese.

\section{Object of Present Work}

This investigation was done because, whilst it was observed that obesity is very common among adult hospital medical out-patients and was either directly responsible for their symptoms or exacerbated the diseases for which they attended, the treatment of the condition was only successful in a minority of cases. In view of this it seemed important to study the subject, and to attempt to discover how far obesity in later life is due to persistent juvenile obesity.

\section{Material and Method}

The age, sex, height and weight were recorded in 373 patients seen consecutively in the medical outpatient department at St. James' Hospital, Balham, and the results were compared with the standard tables of Kemsley (1952).

One hundred and one patients seen in outpatients who were $20 \%$ or more overweight were selected for further study. These are the 'obese' group, and were sub-divided into "juvenile obese" and 'adult obese' groups according to whether or not they had been known as 'fatty' at school; this was found to be the most practical single criterion.

Fifty patients whose weight was within $20 \%$ of normal weight were studied in a similar way. They were chosen primarily for co-operation and intelligence. An attempt to take detailed life and dietary histories from an unselected series of out-patients of normal weight was abandoned and it was decided that, in spite of the differences between the two groups, intelligent and co-operative subjects would provide more valuable information which could later be used for more standardized studies. Thus the two groups can be compared in some respects, but the 'normals' rannot be regarded as 'controls'.

Twenty-one adults who had received medical treatment for obesity during childhood were investigated in the same way, special attention being paid to possible reasons why their obesity had persisted or resolved. This is the 'treated juvenile obese' group.

Seven patients in the 'treated juvenile obese' group and three in the normal group had suffered from juvenile obesity and later become normal.
These were classed together as the 'normal juvenile obese' group.

Each patient was asked the history of her weight and its relation to her life-circumstances. An attempt was made to assess her appetite and type of diet and the factors influencing these. Special attention was paid to early and family history, the influence of pregnancy, and to possible medical and psychological factors influencing the condition. In addition, the usual medical history was taken, a full clinical examination was done in every case and any investigations thought necessary were carried out.

An attempt was made to treat all these patients as out-patients. The method of treatment was primarily dietary with the object of accustoming the patients to a bulky low-calorie diet and of reeducating their eating habits rather than of producing rapid and temporary loss of weight. Drugs, chiefly dextroamphetamine sulphate, were used when it did not seem possible to treat the patient by dietary means alone.

\section{Overall Results}

Incidence of Overweight. The impression that obesity is common among the patients was confirmed (Fig. 1). Of the 373 medical out-patients $36 \%$ of the men and $52 \%$ of the women were more than $10 \%$ above standard weight. Twenty-six per cent of the men and $44 \%$ of the women were

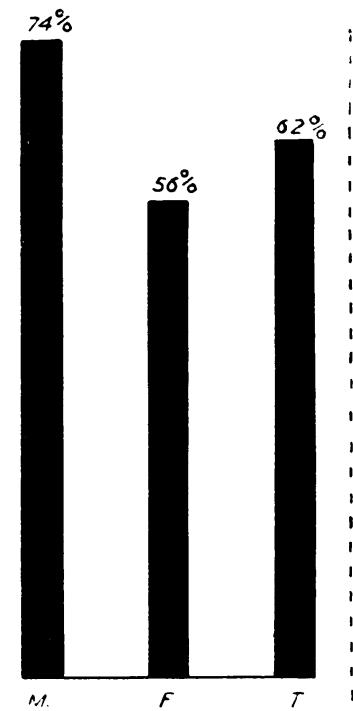

NORMAL OR UNDERWEIGHT

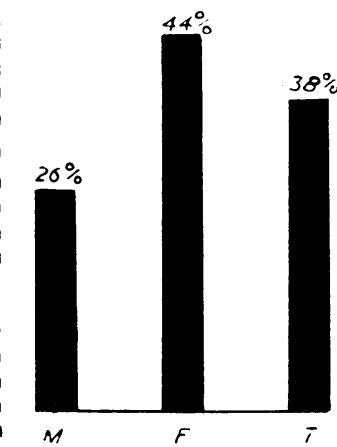

OBESE (MORE THAN 20\% OVER IDEAL WE/GHT)

FIG.1.--Incidence of obesity in 373 medical out-patients. M. Male; F. Female: T. Total. 
more than $20 \%$ above standard weight, and so were classed as 'obese'. It is interesting to note that a higher percentage of the women $(21 \%)$ than the men $(14 \%)$ were also underweight, and that only $26 \%$ of the women, compared with $51 \%$ of the men were within $10 \%$ of standard weight.

Obese Group. Table 1 shows the distribution of age, sex and type of obesity in the 101 obese patients. Of these approximately one third were cases of persistent juvenile obesity and in the remaining two thirds the obesity developed later in life.

TABLE 1

DISTRIBUTION OF 101 OBESE PATIENTS ACCORDING TO AGE, SEX AND TYPE OF OBESITY

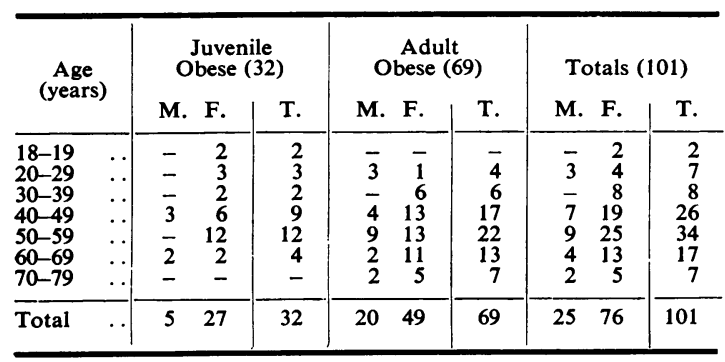

Table 2 and Fig. 2 record the severity of the obesity in the obese group, and show that the condition tended to be more severe in the juvenile obese group than in the adult obese group.
It was not possible to discover the age at onset of the obesity in all the relatives, but the impression gained from those who could remember was that the obese husbands and wives of the obese group tended to become obese after marriage, and that the obese daughters of obese women tended to become obese at the same age as their mothers. There were, however, exceptions to this and one case was seen in which obesity developed rapidly in both mother and son simultaneously.

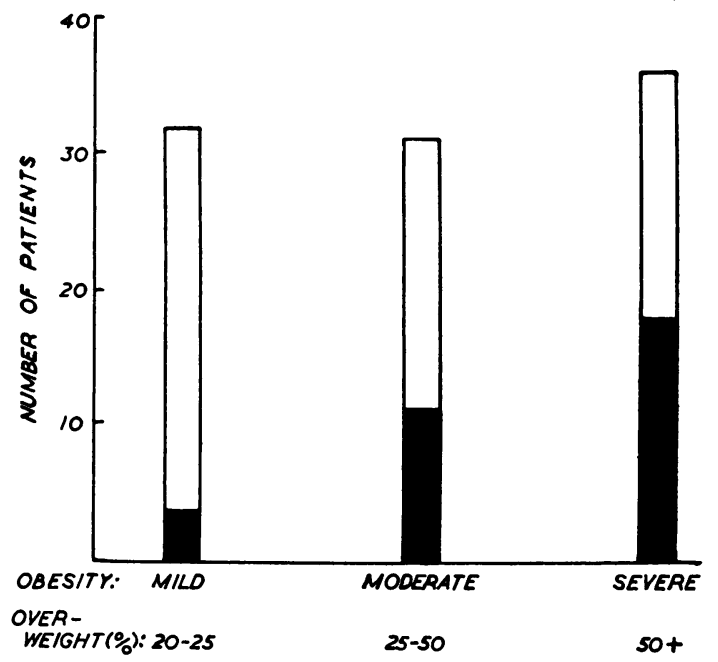

FIG. 2.-Histogram showing proportion of juvenile-type obesity in 101 obese patients. Juvenile obese. Adult obese.

TABLE 2

SEVERITY OF OBESITY IN 101 OBESE PATIENTS

\begin{tabular}{|c|c|c|c|c|c|c|c|c|c|c|c|c|c|}
\hline \multirow[t]{2}{*}{ Severity } & & & \multicolumn{4}{|c|}{ Juvenile Obese (32) } & \multicolumn{4}{|c|}{ Adult Obese (69) } & \multicolumn{3}{|c|}{ Totals (101) } \\
\hline & & & M. & F. & T. & $\%$ & M. & F. & T. & $\%$ & M. & F. & T. \\
\hline $\begin{array}{l}\text { Mild ( } 20 \%-25 \% \text { overweight) } \\
\text { Moderate ( } 25 \%-50 \% \text { overweight) } \\
\text { Severe (more than } 50 \% \text { overweight) }\end{array}$ & $\begin{array}{l}\cdots \\
\cdots \\
\cdots\end{array}$ & $\begin{array}{l}\cdots \\
\cdots \\
\cdots\end{array}$ & $\overline{3}$ & $\begin{array}{r}4 \\
8 \\
15\end{array}$ & $\begin{array}{r}4 \\
11 \\
17\end{array}$ & $\begin{array}{l}12 \\
35 \\
53\end{array}$ & $\begin{array}{r}10 \\
7 \\
3\end{array}$ & $\begin{array}{l}18 \\
14 \\
17\end{array}$ & $\begin{array}{l}28 \\
21 \\
20\end{array}$ & $\begin{array}{l}41 \\
30 \\
29\end{array}$ & $\begin{array}{r}10 \\
10 \\
5\end{array}$ & $\begin{array}{l}22 \\
22 \\
32\end{array}$ & $\begin{array}{l}32 \\
32 \\
37\end{array}$ \\
\hline
\end{tabular}

Family History. Table 3 and Fig. 3 show the incidence of obesity in the families of the obese and normal groups. Obesity occurred more frequently in the near relatives of the juvenile obese group than in the adult obese group. In the normal group there was a lower incidence of obesity among all the relatives, and this was most marked in the father and spouse. Fifty per cent of the juvenile obese group had obese fathers compared with only $2 \%$ of the normal group, and $22 \%$ of the juvenile obese group were married to obese people compared with $4 \%$ of the normal group.
Influence of Pregnancy and Menopause. It is well known that women tend to become obese during pregnancy and at the menopause and that those who are already obese tend to become more obese at these times (Gurney, 1936; Greene, 1939; Sheldon, 1949; Richardson, 1952). It has also been observed (Sheldon, 1949; Richardson, 1952) that women who were overweight at marriage were more likely to gain excessive weight due to deposition of fat during pregnancy, than those whose weight was normal at marriage. It might therefore be expected that women with persistent juvenile 
obesity tend to become even more obese with pregnancy. The present findings do not appear to confirm this (Table 4 ). Only $44 \%$ of the juvenile
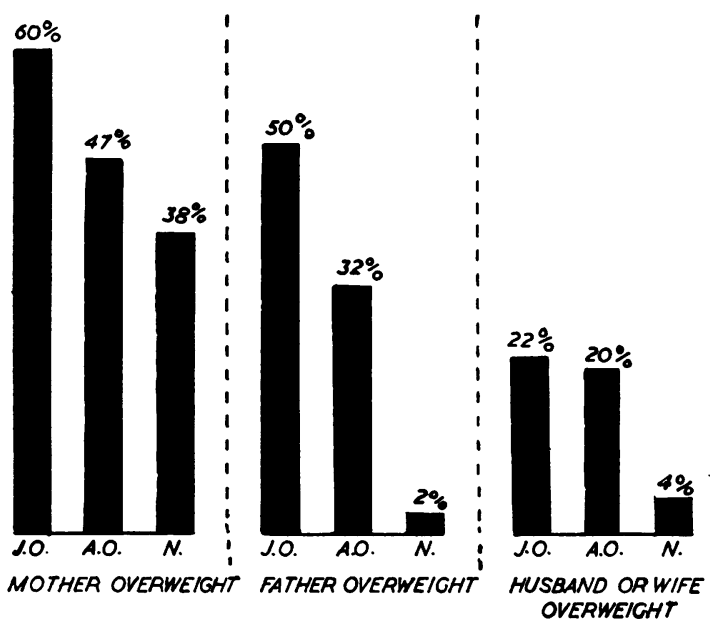

FIG. 3.-Incidence of obesity in parents and spouses of 101 obese patients and 50 patients of normal weight.

J.O. = Juvenile obese; A.O. $=$ Adult obese N. $=$ Normal. obese group compared with $72 \%$ of the adult obese group and $53 \%$ of the normal group gained weight excessively in pregnancy, and afterwards had to wear clothes of a larger size. The numbers are small, but if the difference is real it does not necessarily conflict with the findings of Sheldon and Richardson. In a recent personal study of maternal obesity it was found that those who were overweight at marriage were prone to develop maternal obesity, but even more prone were those who had been overweight at some time before marriage and had reduced their weight. The difference was accounted for by those who had never tried to reduce their weight, among whom the incidence of maternal obesity was low. Although the exact age of onset of the obesity was not recorded, it is possible that these were cases of persistent juvenile obesity.

Only two women $(7 \%)$ in the juvenile obese group had gained excessive weight at the menopause, compared with $12(25 \%)$ of the adult obese group.

The figures suggest, therefore, that persistent juvenile obesity increases less during the physio-

TABLE 3

FAMILY HISTORY OF OBESITY IN 101 OBESE PATIENTS COMPARED WITH 50 PATIENTS OF NORMAL WEIGHT

\begin{tabular}{|c|c|c|c|c|c|c|c|c|c|c|c|}
\hline \multicolumn{4}{|l|}{ Relative } & \multicolumn{2}{|c|}{ Juvenile Obese (32) } & \multicolumn{2}{|c|}{ Adult Obese (69) } & \multicolumn{2}{|c|}{ Totals (101) } & \multicolumn{2}{|c|}{ Normal Group (50) } \\
\hline $\begin{array}{l}\text { Mother: } \\
\text { Overweight } \\
\text { Normal }\end{array}$ & $\begin{array}{l}\ldots \\
\cdots\end{array}$ & $\begin{array}{l}\ldots \\
\ldots\end{array}$ & $\begin{array}{l}\cdots \\
\cdots\end{array}$ & $\begin{array}{l}\text { No. } \\
20 \\
11\end{array}$ & $\begin{array}{l}\% \\
62 \\
34\end{array}$ & $\begin{array}{c}\text { No. } \\
32 \\
27\end{array}$ & $\begin{array}{l}\% \\
46 \\
39\end{array}$ & $\begin{array}{c}\text { No. } \\
52 \\
38\end{array}$ & $\begin{array}{l}\% \\
51 \\
38\end{array}$ & $\begin{array}{c}\text { No. } \\
19 \\
26\end{array}$ & $\begin{array}{l}\% \\
38 \\
52\end{array}$ \\
\hline $\begin{array}{l}\text { Father: } \\
\text { Overweight } \\
\text { Normal }\end{array}$ & $\begin{array}{l}\ldots \\
\cdots\end{array}$ & $\begin{array}{l}\ldots \\
\ldots\end{array}$ & $\begin{array}{l}\cdots \\
\cdots\end{array}$ & $\begin{array}{l}16 \\
14\end{array}$ & $\begin{array}{l}50 \\
44\end{array}$ & $\begin{array}{l}22 \\
34\end{array}$ & $\begin{array}{l}32 \\
49\end{array}$ & $\begin{array}{l}38 \\
48\end{array}$ & $\begin{array}{l}38 \\
48\end{array}$ & $\begin{array}{r}1 \\
43\end{array}$ & $\begin{array}{r}2 \\
86\end{array}$ \\
\hline $\begin{array}{l}\text { One or more sisters: } \\
\text { Overweight }\end{array}$ & $\cdots$ & $\cdots$ & $\cdots$ & 15 & 47 & 28 & 41 & 43 & 43 & 14 & 28 \\
\hline $\begin{array}{l}\text { One or more brothers: } \\
\text { Overweight }\end{array}$ & . & $\cdots$ & $\cdots$ & 13 & 41 & 22 & 32 & 35 & 35 & 2 & 4 \\
\hline $\begin{array}{c}\text { Husband or wife: } \\
\text { Overweight } \\
\text { Normal }\end{array}$ & $\begin{array}{l}\text {. } \\
\therefore\end{array}$ & $\begin{array}{l}\cdots \\
\cdots\end{array}$ & 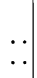 & $\begin{array}{r}7 \\
18\end{array}$ & $\begin{array}{l}22 \\
56\end{array}$ & $\begin{array}{l}14 \\
36\end{array}$ & $\begin{array}{l}20 \\
52\end{array}$ & $\begin{array}{l}21 \\
54\end{array}$ & $\begin{array}{l}21 \\
53\end{array}$ & $\begin{array}{r}2 \\
35\end{array}$ & $\begin{array}{r}4 \\
70\end{array}$ \\
\hline
\end{tabular}

The apparent discrepancies in the figures are due to patients who could not remember their parents or who were not married.

TABLE 4

EXCESSIVE WEIGHT GAIN IN PREGNANCY IN 101 OBESE PATIENTS COMPARED WITH 50 PATIENTS OF NORMAL WEIGHT

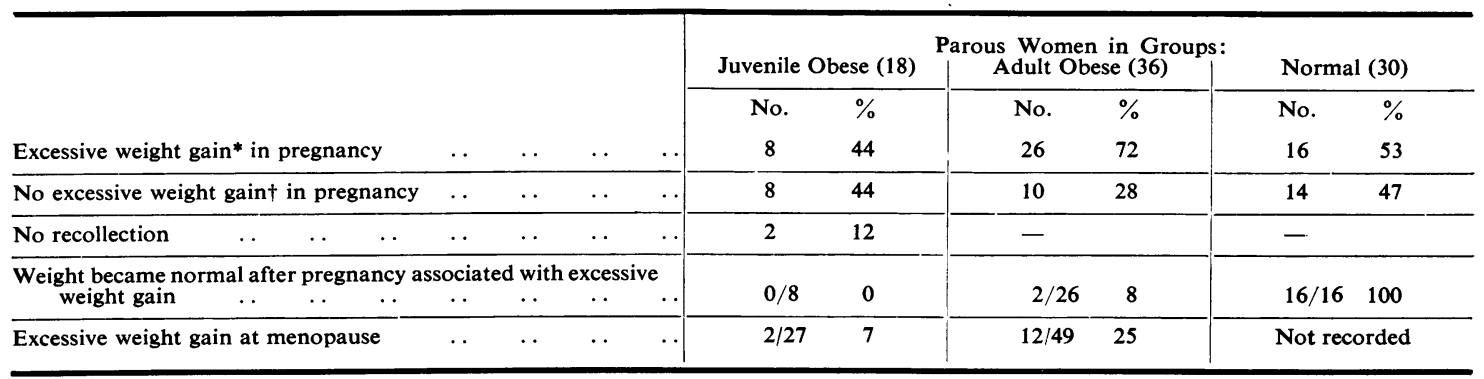

* i.e. wore larger clothes after pregnancy. $\dagger$ i.e. wore same size of clothes after pregnancy. 
logical changes of pregnancy and the menopause than other types of obesity.

Types of Appetite. Most authorities stress the alimentary cause of juvenile obesity. Østergaard (1954) found that none of his control group with large appetites gave the impression of eating urges comparable with those found in some of his obese group. Kerley and Lorenze (1941) state: 'These children are alike in possessing habitually insatiable appetites and a capacity for excessive food intake without resulting illness'. They also found that obese children had a preference for sweet and starchy foods.

In the juvenile obese group, 25 patients $(78 \%)$ admitted to large appetites, and their replies were substantiated by further questions as to food intake. This compared with $28(41 \%)$ of the adult obese group and $14(28 \%)$ of the normal group. A preference for sweet, starchy and fried foods was common among the obese, but the normal subjects with large appetites usually ate bulky and savoury foods in preference to sweet, though they too mostly liked fried foods.

It is well recognized that psychological factors can play a large part in the aetiology of obesity. The frequency with which they are said to occur varies according to the worker, the criteria and the selection of patients. Bruch (1940), studying obese children in hospital practice, found that specific psychological factors were the most important in the production of obesity. Juel-Nielsen (1953) found psychological difficulties in nine out of 60 obese schoolchildren, and Iversen (1953) in 16 out of 40 . Both these workers found that the psychological factors were less specific than in Bruch's series.

Psychiatric histories taken in the present series were no more detailed than those taken by any careful physician except that their possible connexion with appetite and food intake was carefully noted. Psychological factors that appeared to lead to increased food intake were found on the first interview in $17(53 \%)$ of the juvenile obese group, $34(49 \%)$ of the adult obese group and nine $(18 \%)$ of the normal group. The patients were found to be of two main types:

(1) Those who normally reacted to worry and nervous tension by increase of food intake. This was by far the commonest type (Table 5). Probably most people, both normal and obese, react to stress by decrease of appetite and, if the stress is prolonged, by loss of weight. It is recognized, however, that some people react to mild and sometimes even to severe stress by increased food intake. Johnson (1947) quotes an interesting case of a thin husband and a plump wife submitted to the same psychological stress. The husband lost $13 \mathrm{lb}$. in weight and the wife gained $26 \mathrm{lb}$. before their worry ended. Freed (1947) asked 500 patients under treatment for obesity whether they ate more when nervous or worried; $370(74 \%)$ answered 'yes'. The patients in the present series were asked the same question (Table 5). The incidence among the obese is much lower than in Freed's group, but it is nevertheless high, and is higher in the juvenile obese than in the other groups. Many patients admitted freely to this reaction and were well aware of it; others had not previously thought about it, but on being questioned they admitted that overeating was their usual reaction to stress. The overeating was usually non-specific, though in a few patients a specific craving for a particular food occurred and their descriptions of this sounded very much like the pica that is known to occur in pregnancy, and sometimes seemed to be associated with it.

\section{TABLE 5}

INFLUENCE OF WORRY AND PSYCHOLOGICAL STRESS ON APPETITE IN OBESE AND NORMAL PATIENTS

\begin{tabular}{|c|c|c|c|c|c|c|c|c|}
\hline \multicolumn{3}{|c|}{$\begin{array}{l}\text { Effect of Stress } \\
\text { on Appetite }\end{array}$} & \multicolumn{2}{|c|}{$\begin{array}{c}\text { Juvenile } \\
\text { Obese (32) }\end{array}$} & \multicolumn{2}{|c|}{$\begin{array}{c}\text { Adult } \\
\text { Obese (69) }\end{array}$} & \multicolumn{2}{|c|}{$\begin{array}{c}\text { Normal } \\
\text { Group (50) }\end{array}$} \\
\hline Increased & . & . & $\begin{array}{c}\text { No. } \\
14\end{array}$ & $\begin{array}{l}\% \\
44\end{array}$ & $\begin{array}{l}\text { No } \\
18\end{array}$ & $\begin{array}{l}\% \\
26\end{array}$ & $\begin{array}{c}\text { No. } \\
9\end{array}$ & $\begin{array}{l}\% \\
18\end{array}$ \\
\hline Decreased & . & . & 8 & 25 & 20 & 29 & 31 & 62 \\
\hline Unaffected & & $\cdots$ & 10 & 32 & 31 & 45 & 10 & 20 \\
\hline
\end{tabular}

M.J., aged 38 and $74 \%$ overweight, had been obese all her life and had increased markedly in weight during three pregnancies. Her father, mother, husband and daughter were all obese. Since childhood she had had a craving for milk chocolate which she tried to control. Normally she managed to restrict herself to $\frac{1}{4} \mathrm{lb}$. a week, but when worried or pregnant she could not pass a sweet shop without buying a bar and during these times ate at least $\frac{1}{2}$ lb. every day.

It is interesting to note that the excessive eating reaction to stress was found in only $9(18 \%)$ of the normal group.

(2) The second group were those in whom obesity developed or increased rapidly in association with a specific psychological trauma. Shorvon and Richardson (1949) described six such cases in adults. Østergaard (1954) describes obesity in children associated with a death in the family, separation of the parents or the birth of a baby. Three patients $(9 \%)$ in the juvenile group and $13(19 \%)$ in the adult group were of this type. It is probable that a 
specific trauma of this kind is less likely to be recalled if it occurred in childhood than in adult life.

\section{Results of Treatment}

Bruch (1955) and Stuart (1955) found that obesity which had developed in childhood was particularly difficult to treat. The results of treatment in the obese group confirm these findings.

The criteria of success were:

(1) Poor. This group includes patients who failed to lose more than $30 \%$ of their excess weight during at least four months' treatment, and those who, within this time and before any success had been achieved, ceased to attend the clinic.

(2) Moderate. This group includes those who, during treatment lasting at least four months, lost more than $30 \%$ of their excess weight but who did not reduce their weight to within $20 \%$ of standard weight, or, in cases of mild obesity, to within $10 \%$ of standard weight.

(3) Good. This group includes all patients who reduced to within $10 \%$ of standard weight and all patients with moderate or severe obesity who reduced to within $20 \%$ of standard weight.

(4) Not yet known. This group includes all patients who had been under treatment for less than four months and who were still attending at the time of writing.

Most of the patients in groups (2) and (3) are still under treatment, and therefore it is hoped that the ultimate results will be better.

The results of treatment are shown in Table 6.

TABLE 6

RESULTS OF TREATMENT OF OBESITY

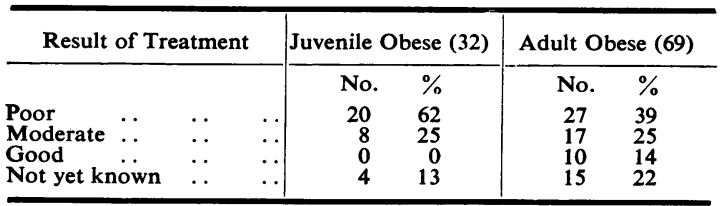

The incidence of failure is much higher in the juvenile type than in the adult type. So far, treatment has not resulted in complete success in a single case in the juvenile group. However, the fact that a quarter of them have lost more than $30 \%$ of their original excess weight is hopeful, since all these patients are still under treatment. The fact that, not only the incidence, but also the degree of success appears to be greater in the adult than in the juvenile group may be due to the higher incidence of severe obesity in the juvenile group and, therefore, the longer time necessary before complete success is achieved. Nearly all the patients in whom some success has been achieved are still attending the clinic at the time of writing.

A common difficulty in treating obesity is the appearance of new symptoms which appear to be related to the diet. Symptoms of hunger, mild depression and constipation are so common that they can be expected. Severe reactions, however, also occur, and, if they are not successfully treated, usually herald the failure of treatment, and the patient's failure to keep further appointments. Common among the more severe reactions are uncontrollable hunger and craving for food, severe depression, hysterical outbursts, flatulence, abdominal pain, an overwhelming preoccupation with bowel action, headaches, giddiness, faintness, nightmares and bizarre symptoms. Severe reactions occurred in nine patients $(28 \%)$ of the juvenile group and in seven patients $(10 \%)$ of the adult group who continued to attend the clinic (Table 7). It is probable that they were the cause of failure in some other patients to attend the clinic. When psychological complications were absent, severe reactions occurred in about a fifth of both juvenile and adult obese groups. When the complications were present, however, though severe reactions were twice as frequent in the juvenile obese, in the adult obese group they occurred only half as commonly as in the adult obese without psychological complications. The adult obese group with obvious psychological complications were more amenable to treatment than those without, whereas in the juvenile group the situation is reversed. Since these reactions often lead to failure to keep appointments, and the incidence of failure is also higher

TABLE 7

INCIDENCE OF SEVERE PSYCHOLOGICAL REACTIONS TO TREATMENT IN 101 OBESE PATIENTS

\begin{tabular}{|c|c|c|c|c|c|c|c|c|c|c|c|c|}
\hline \multirow[b]{3}{*}{ All patients } & \multirow[b]{3}{*}{$\cdots$} & \multirow[b]{3}{*}{. } & \multirow[b]{3}{*}{$\cdots$} & \multirow[b]{3}{*}{$\cdots$} & \multirow[b]{3}{*}{$\cdots$} & \multirow[b]{3}{*}{$\ldots$} & \multicolumn{3}{|c|}{ Juvenile Obese } & \multicolumn{3}{|c|}{ Adult Obese } \\
\hline & & & & & & & No. & Reactions & $\%$ & No. & Reactions & $\%$ \\
\hline & & & & & & & 32 & 9 & 28 & 69 & 7 & 10 \\
\hline \multicolumn{4}{|c|}{ With apparent psychological factors } & $\cdots$ & $\cdots$ & $\cdots$ & 17 & 6 & 35 & 34 & 2 & 6 \\
\hline \multicolumn{4}{|c|}{ Without apparent psychological factors } & $\ldots$ & $\cdots$ & $\cdots$ & 15 & 3 & 20 & 35 & 5 & 15 \\
\hline
\end{tabular}


in the juvenile group, it seems likely that these reactions are an important cause of the higher incidence of failure in the treatment of the juvenile group.

Since most of these patients are still under treatment, it is probable that the ultimate incidence of severe reactions occurring among them will be higher than at present recorded.

Treated Juvenile Group. Of 21 adult patients who had been under medical care for obesity in childhood, 10 were still obese, and most of these were severely obese. Four were exceptionally tall and overweight, but not obese, and seven (five females and two males) were of normal height and within $20 \%$ of normal weight. The findings agree in the main with those of other workers (Bornhardt, 1936; Hering, 1938; Mossberg, 1948; Le Marquand, 1951; Haase and Hosenfeld, 1956).

Of the 10 patients who were still obese, four had lost weight during treatment in childhood, but none had become normal. The remaining six had not lost weight. Five of the group, as far as could be ascertained from the records, had failed to keep further appointments, presumably due to parental influence. The four patients who had grown exceptionally tall had not responded to treatment in childhood but all stated that they ceased to be obese during a later period of rapid growth, and in three of them this coincided with markedly increased activity.

Normal Juvenile Obese Group. In the 10 patients who had been under medical care for obesity in childhood and whose weight as adults was within $20 \%$ of normal weight there were several outstanding features:

(1) All these patients were at least $5 \%$ above standard weight, and none of them had ever been below it.

(2) With one exception they were all highly intelligent, compared with most other patients attending the hospital. Nine of the $10(90 \%)$ had had a grammar school education. Among the 101 ratients in the 'obese' group, only six $(6 \%)$ had had a grammar school education and a large number appeared to be of very low intelligence. Only one of the 'treated juvenile obese' group who had remained obese had been to a grammar school.

Dorff (1935) found that obese children tended to be retarded. Bronstein, Wexler, Brown and Halpern (1942) found that the mean intelligence of obese children was higher than the mean of the general population, but found a tendency among them to be of either superior or retarded development. Østergaard (1954) found a normal distribution of intelligence among obese children and agreed with Bruch (1940) that serious obesity occurs less frequently under good social conditions than poor. In all the patients seen during the present investigation, there has been no case of severe obesity who had had a grammar school education, and, before the outstanding incidence of high intelligence in children who became normal was realized, a strong clinical impression was formed that the degree of success achieved in the treatment of adults was closely related to the intelligence of the patient.

(3) The mothers of these patients were intelligent and co-operative, and those who were themselves overweight (seven out of 10) made strong and successful, if sometimes intermittent, attempts to control their own weights.

(4) Weight reduction is associated with increased activity. In some cases increased activity followed weight reduction by dietary means. In others it seemed to occur spontaneously.

\section{Discussion and Conclusion}

Every case of obesity is 'exogenous' in that it is due to an intake of calories greater than the amount required for standard body weight. It can be argued that every case of obesity is 'endogenous' in that the cause for the excessive intake lies within the patient. Every case of obesity can be cured by reduction of caloric intake relative to the body's needs. Yet, in a very high proportion of cases, the condition seems untreatable by the methods in common use because the patient continues to eat in excess of the amount required for weight loss. Since this depends far more on the patient than on the doctor, a sense of hopelessness is easily induced in the minds of physicians attempting to treat the condition. Nevertheless its dangers make it important to increase our knowledge and to attempt to treat the condition whenever it is seen.

Approximately one third of all patients attending medical out-patients were found to be obese and, of these, approximately one third were found to be cases of persistent juvenile obesity. Thus more than $10 \%$ of medical out-patients had been obese from childhood. These patients did not on the whole appear to differ qualitatively from the other obese patients, but they tended to be more severely obese and a higher incidence of factors known to be associated with obesity was found among them, including large appetites, a family history of obesity and a tendency to eat more when nervous or worried. 
Periods of endocrinological change, such as pregnancy and the menopause, appeared to have less influence on their weights than on those of the adult obese group.

The most marked difference between the two groups was in the results of treatment, which was much less successful in those whose obesity dated from childhood. This seemed to be at least partly due to the higher incidence of failure to keep appointments and of severe reactions to treatment in the juvenile obese group.

It is of interest that in the adult obese group treatment was more successful and the incidence of severe reactions was lower in those with obvious psychological factors complicating the obesity than in those who appeared normally adjusted. The reverse is the case in those whose obesity has been present since childhood.

In considering those patients who had suffered from juvenile obesity and who later became normal, the outstanding difference between them and those who remained obese lay in their intelligence. This finding confirmed a previous impression that intelligence is an important factor in the prevention of obesity and in the success of treatment. The present findings suggest that the usual methods of treatment are adequate for most intelligent obese children, but inadequate for the less intelligent, and it is felt that this is probably true for most adults too. The obese adult of low intelligence who has been obese since childhood or who has become addicted to food in later life is probably the most difficult of all patients to treat for obesity.

It is concluded that persistent juvenile obesity is an important cause of obesity in adult life and is, therefore, a potentially dangerous condition.

Juvenile obesity that persists into adult life tends to be more severe and more difficult to treat than obesity occurring in adult life.

Psychological factors play a larger part in persistent juvenile obesity than in adult obesity and are an important cause of failure of treatment.

The prognosis in juvenile obesity, and probably also in adult obesity, depends largely on the intelligence of the patient.

Every effort should be made to treat obesity when it first occurs.

Research should be directed particularly towards the treatment of obesity in patients of low intelligence.

I am grateful to Dr. Alexander Kahan, of St. James's Hospital, on whose patients this investigation was done. I should like to thank Dr. J. C. Burkinshaw and Mr. M. P. Curwen for information and advice, Mr. F. A. Tubbs, Librarian of St. Thomas's Hospital and his staff and Miss M. E. Charlton, Records Officer of St. James's Hospital for their assistance, Miss E. Mason for drawing the diagrams and Mrs. J. Smith for untiring secretarial assistance.

\section{REFERENCES}

Armstrong, D. B., Dublin, L. I., Wheatley, G. M. and Marks, H. H. (1951). J. Amer. med. Ass., 147, 1007.

Bornhardt, M. (1936). Mschr. f. Kinderheilk, 67, 270.

Bronstein, I. P., Wexler, S., Brown, A. W. and Halpern, L. J. (1942). Amer. J. Dis. Child., 63, 238.

Bruch, H. (1939). Amer. J. Dis. Child., 58, 1001.

- (1940). Ibid., 59, 739; 60, 1082

(1941). J. Pediat., 19, 365.

(1955). Ann. N.Y. Y. Acad. Sci., 63, 68

(1957). The Importance of Overweight. New York.

Dorff, G. B. (1935). J. Pediat., 6, 788.

Dublin, L. I. (1953). Amer. J. publ. Hlth., 43, 993.

Ellis, R. W. B. and Tallerman, K. H. (1934). Lancet, 2, 615.

Evans, F. A. (1952). In Duncan, G. G. Diseases of Metabolism, 3rd ed. Philadelphia.

Freed, S. C. (1947). J. Amer. med. Ass., 133, 369.

Greene, J. A. (1939). Ann. int. Med., 12, 1797.

Gurney, R. (1936). Arch. int. Med., 57, 557.

Haase, K. E. and Hosenfeld, H. (1956). Z. Kinderheilk, 78, 1

Hansson, R., Brännäng, E. and Claesson, O. (1953). Acta agric. scand., 3, 61 .

Hässler, - (1935). Mschr. f. Kinderheilk, 63, 404.

Hering, S. (1938). Ibid., 73, 11

Iversen, T. (1953). Acta Paediat., 42, 8.

Johnson, W. M. (1947). J. Amer. med. Ass., 133, 1238.

Johnson, M. L., Burke, B. S. and Mayer, J. (1956). Amer. J. clin. Nutrit., $4,37$.

Jolliffe, N. (1953). Amer. J. publ. Hith, 43, 989.

Juel-Nielsen, N. (1953). Acta Paediat, 42, 130

Kemsley, W. F. F. (1952). Ann. Eugen. Lond., 16, 316.

Kennedy, G. C. (1951). Proc. roy. Soc. Med., 44, 899.

- (1955). Voeding, 16, 40.

Kerley, C. G. and Lorenze, E. J. (1941). J. Pediat., 19, 241.

Le Marquand, H. S. (1951). Proc. roy. Soc. Med., 44, 458, 952.

McCay, C. M., Maynard, L. A., Sperling, G. and Osgood, H. S. (1941). J. Nutr., 21, 45.

Marks, H. H. (1956). Human Biology, 28, 217.

Mossberg, H. O. (1948). Acta Paediat., 35, Suppl. 2.

Østergaard, L. (1954). Ibid., 43, 507.

Richardson, J. S. (1952). Lancet, 1, 525.

Sheldon, J. H. (1949). Ibid., 2, 869.

Shorvon, H. J. and Richardson, J. S. (1949). Brit. Med. J., 2, 951.

Sinclair, H. M. (1954). Oxford Meeting of the British Association.

Stuart, H. C. (1955). Quart. Rev. Pediat., 10, 31. 